\title{
Are D-manno-configured Amadori products ligands of the bacterial lectin FimH?
}

\author{
Tobias-Elias Gloe ${ }^{\ddagger 1}$, Insa Stamer ${ }^{\ddagger 1}$, Cornelia Hojnik ${ }^{\ddagger 2}$, Tanja M. Wrodnigg ${ }^{\star 2}$ \\ and Thisbe K. Lindhorst ${ }^{* 1}$
}

\author{
Full Research Paper \\ Address: \\ ${ }^{1}$ Christiana Albertina University of Kiel, Otto Diels Institute of Organic \\ Chemistry, Otto-Hahn-Platz 3/4, D-24118 Kiel, Germany, Fax: +49 \\ 4318807410 , and ${ }^{2}$ Glycogroup, Institute of Organic Chemistry, \\ Technical University Graz, Stremayrgasse 9, A-8010 Graz, Austria \\ Email: \\ Tanja M. Wrodnigg ${ }^{*}$ - t.wrodnigg@tugraz.at; Thisbe K. Lindhorst ${ }^{*}$ - \\ tklind@oc.uni-kiel.de \\ * Corresponding author $\ddagger$ Equal contributors \\ Keywords: \\ Amadori rearrangement; bacterial adhesion; $C$-mannosides; docking \\ studies; FimH ligands
}

Beilstein J. Org. Chem. 2015, 11, 1096-1104. doi:10.3762/bjoc. 11.123

Received: 24 February 2015

Accepted: 13 June 2015

Published: 30 June 2015

Associate Editor: K. N. Ganesh

(C) 2015 Gloe et al; licensee Beilstein-Institut. License and terms: see end of document.

\begin{abstract}
The Amadori rearrangement was employed for the synthesis of $C$-glycosyl-type D-mannoside analogues, namely 1-propargylamino- and 1-phenylamino-1-deoxy- $\alpha$-D-manno-heptopyranose. They were investigated as ligands of type 1-fimbriated $E$. coli bacteria by means of molecular docking and bacterial adhesion studies. It turns out that Amadori rearrangement products have a limited activity as inhibitors of bacterial adhesion because the $\beta$ - $C$-glycosidically linked aglycone considerably hampers complexation within the carbohydrate binding site of the type 1-fimbrial lectin FimH.
\end{abstract}

\section{Introduction}

The Amadori rearrangement (AR) is the reaction in which aldohexoses react with suitable amines under acidic catalysis to 1-amino-1-deoxyketohexoses ( $C$-glycosyl-type pentose analogues) without the need of hydroxy group protection (Scheme 1). For a long time this reaction has been judged as unsuitable for preparative use as it typically leads to a complex mixture of products accompanied with a low yield of the rearrangement product itself [1]. However, we could show that the Amadori rearrangement, when applied to selected aldoses as starting materials, is a high yielding and efficient synthetic approach towards $C$-glycosyl-type glycoconjugates. For example, when aldoheptoses are employed as starting material for the Amadori rearrangement, the respective 1-amino-1-deoxyketoheptoses ( $C$-glycosyl-type hexose analogues) can be obtained in exclusively one anomeric form as well as in excellent yields (Scheme 1) [2,3]. Thus, the Amadori rearrangement can be utilised to convert a respectively configured aldoheptose into a $C$-glycosyl-type glycoconjugate in one step and without the need of protecting group manipulations. This is intriguing in light of biorthogonal ligation methodology as Amadori products are structurally closely related to naturally occurring D-hexopyranosides. In addition, $C$-glycosyl glycoconjugates are 
<smiles>[R]C(O)[C@H]1O[C@H](O)[C@@H](O)[C@@H](O)[C@@H]1O</smiles>

Aldohexose $(\mathrm{R}=\mathrm{H})$

Aldoheptose $\left(\mathrm{R}=\mathrm{CH}_{2} \mathrm{OH}\right)$

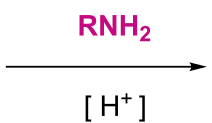

Hexose analogues $\left(\mathrm{R}=\mathrm{CH}_{2} \mathrm{OH}\right)$

Scheme 1: The Amadori rearrangement of aldoses with amines leads to $C$-glycosyl-type glycoconjugates, namely 1-amino-1-deoxyketoses.

believed to bear great potential as therapeutics and as tools for mechanistic studies in biology. This is because they are not sensitive towards enzymatic hydrolysis such as in physiological environment, in contrast to the naturally occurring $O$ - and $N$-glycosides.

With respect to our long-lasting interest in the design and investigation of ligands for the bacterial lectin FimH [4] it has been our goal to investigate the Amadori rearrangement as a method to approach new FimH ligands. These are especially relevant in the context of an anti-adhesion therapy against bacterial infections [5,6]. As FimH-mediated adhesion to the glycosylated surface of host cells is a key step in infections caused by type 1-fimbriated bacteria, FimH antagonists that inhibit bacterial adhesion can be valuable for treatment of infectious diseases $[7,8]$. The structure of type 1 -fimbrial lectin FimH has been elucidated in X-ray analysis [9-11]. Obviously, FimH binds $\alpha$-D-mannosides such as simple methyl $\alpha$-D- mannoside (MeMan, 1) but not $\beta$-mannosides. Mannosides with an aromatic aglycone, such as $p$-nitrophenyl $\alpha$-D-mannoside ( $p$ NPMan) and 4-methylumbelliferyl $\alpha$-D-mannoside (3) show an improved affinity to FimH due to $\pi-\pi$-stacking interactions of the aromatic moiety with the so-called tyrosine gate at the entrance of the carbohydrate binding site, formed by $\mathrm{Y} 48$ and Y137. Additional interactions exerted by extended aglycone portions can further improve ligand affinity for FimH; for example ortho-chloro substitution of the phenyl ring (compounds $\mathbf{2}$ and $\mathbf{5}$ ), a squaric acid partial structure (compound 4) or heterocyclic substituents such as in indolinylphenyl mannoside 5 as recently introduced [12] (Figure 1).

With the structural requirements of the type 1-fimbrial lectin FimH for its ligands in mind, we addressed the question, if D-manno-configured Amadori products with their axially oriented anomeric hydroxy group can function as a new class of FimH ligands. In addition, we can assume that Amadori prod-<smiles>CO[C@H]1O[C@H](CO)[C@@H](O)[C@H](O)[C@H]1O</smiles>

1 MeMan<smiles>O=[N+]([O-])c1ccc(O[C@@H]2O[C@H](CO)[C@@H](O)[C@H](O)[C@H]2O)c(Cl)c1</smiles>

2<smiles>Cc1cc(=O)oc2cc(O[C@@H]3O[C@H](CO)[C@@H](O)[C@H](O)C3O)ccc12</smiles>

3<smiles>CCOC1C(=O)C(=O)C1Nc1ccc(O[C@@H]2O[C@H](CO)[C@@H](O)[C@H](O)[C@H]2O)c(Cl)c1</smiles>

4<smiles>O=[N+]([O-])c1ccc2c(c1)CCN2c1ccc(O[C@@H]2O[C@H](CO)[C@@H](O)[C@H](O)[C@H]2O)c(Cl)c1</smiles>

5

Figure 1: The bacterial lectin FimH is known to bind $\alpha$-D-mannosides such as methyl $\alpha$-D-mannoside 1 (MeMan) with $I C_{50}$ values in the millimolar range [4]. Based on MeMan (1), the affinity of the pNPMan derivative 2 is 717-times improved [13], that of the methylumbelliferyl mannoside 3 116 times improved [14], that of the squaric ester monoester 46900 times higher [15], and the indolinylphenyl mannoside 5 arrives at an IC 50 of $2.4 \mathrm{nM}[8]$. 
ucts are stable against cleavage by mannosidases, as we found earlier that D-gluco-configured Amadori products are no substrates for glucosidases.

\section{Results and Discussion Synthesis of heptopyranose 8 and Amadori products 9 and 10}

To access manno-configured rearrangement products for the synthesis of FimH ligands, we needed to synthesise the appropriate aldoheptose starting material. Its synthesis starts with the oct-1-enitol derivative $\mathbf{6}$ which can be easily obtained by a Grignard reaction of 2,3:5,6-di- $O$-isopropylidene-D-mannose employing commercially available vinylmagnesium bromide (Scheme 2) [16,17]. This C-elongation approach leads to a mixture of C-2 diastereomers, however, during the Amadori rearrangement this centre is converted to a keto group and thus separation of the C-2 epimeric mixture prior to the Amadori rearrangement is not necessary. Simple ozonolysis of the diastereomeric mixture 6 afforded a mixture of the protected D-glycero-D-galacto- and D-glycero-D-talo-configured heptoses $\mathbf{7 a}$ and $\mathbf{7 b}$ in quantitative yield. After sequential cleavage of the protecting groups, employing Zemplén conditions to remove acetyl groups [18,19] followed by acidic cleavage of the isopropylidene groups, the desired starting material for the Amadori rearrangement, a mixture of D-glyceroD-galacto/D-talo heptopyranoses $(\mathbf{8 a} / \mathbf{b})$ was obtained in an overall yield of $85 \%$ from 6 . This is a synthetic route to aldoheptoses $8 \mathbf{a}$ and $\mathbf{8 b}$ alternative to the one reported [2] with the advantage that the use of environmental hazardous as well as highly toxic $\mathrm{HCN}$ is not required.

Amadori rearrangement of the diasteromeric mixture $\mathbf{8}$ with an amine of choice allows an efficient and versatile approach towards D-manno-configured $C$-glycosyl-type glycoconjugates. In our study, we have employed two different amines in the Amadori rearrangement with $\mathbf{8}$, propargylamine and aniline. Under typical conditions for this reaction [2] 1-progargylamino1-deoxy-D-manno-heptulose 9 and 1-phenylamino-1-deoxy-Dmanno-heptulose $\mathbf{1 0}$ were obtained as pure $\alpha$-anomers in $77 \%$ and $24 \%$ yield, respectively (Scheme 3 ). The low yield of compound 10 may be explained by the low $\mathrm{p} K_{\mathrm{a}}$ value (4.62) of aniline compared to a $\mathrm{p} K_{\mathrm{a}}$ of 8.15 for propargylamine, the latter

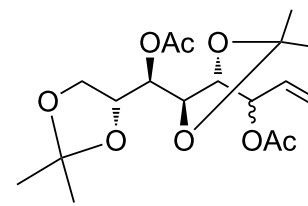

6
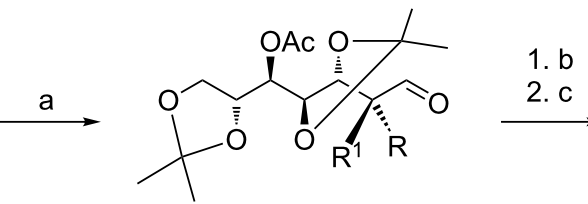

7a $\quad \mathrm{R}=\mathrm{OAc}, \mathrm{R}^{1}=\mathrm{H}$

7b $\quad \mathrm{R}=\mathrm{H}, \mathrm{R}^{1}=\mathrm{OAc}$<smiles>[R]C1([R])C(O)O[C@H]([C@H](O)CO)[C@@H](O)[C@H]1O</smiles>

8a $\quad \mathrm{R}=\mathrm{OH}, \mathrm{R}^{1}=\mathrm{H}$

8b $\quad R=H, R^{1}=O H$<smiles>[R]C1([R])C(O)OC([C@H](O)CO)[C@@H](O)[C@H]1O</smiles>

8a $\quad \mathrm{R}=\mathrm{OH}, \mathrm{R}^{1}=\mathrm{H}$

8b $\quad \mathrm{R}=\mathrm{H}, \mathrm{R}^{1}=\mathrm{OH}$

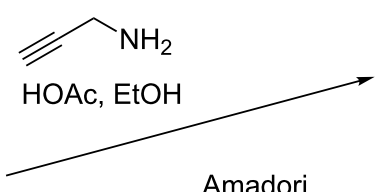

rearrangement

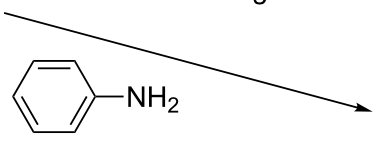

$\mathrm{HOAc}, \mathrm{EtOH}$<smiles>C#CCNC[C@]1(O)O[C@H](CO)[C@@H](O)C(O)C1O</smiles><smiles>OC[C@H]1O[C@@](O)(CNc2ccccc2)[C@H](O)[C@H](O)[C@@H]1O</smiles>

10 
being clearly more efficient as a nucleophile for this type of reaction. Analogous observations have been made in previous studies [20].

Rearrangement products 9 and $\mathbf{1 0}$ exist in their ${ }^{5} \mathrm{C}_{2}$ pyranoid conformation as determined by NMR analysis and can thus indeed be regarded as analogues of $\alpha$-D-mannosides. The $\mathrm{N}$-alkyl/aryl aminomethyl substituent at the anomeric position is found in the sterically favoured equatorial position located towards the $\beta$-face of the sugar ring, whereas the anomeric hydroxy group is $\alpha$-positioned. Whether this particular $C$-type glycoside architecture is suited for FimH complexation had to be tested.

\section{Theoretical consideration of Amadori prod- ucts $\mathbf{9}$ and $\mathbf{1 0}$ as FimH ligands}

The complexation of MeMan (1, cf. Figure 1) as the most simple FimH ligand in the carbohydrate binding site of FimH has been described in detail [10]. It is depicted in a simplified cartoon fashion in Figure 2. The $\alpha$-configured aglycone moiety $\left(\mathrm{OCH}_{3}\right.$ in green) of the glycoside is pointing out of the binding site, whereas the axial 2-OH group as well as all other hydroxy groups of the sugar ring are complexed within the FimH carbohydrate binding site. Complexation of mannoside ligands is further supported by a conserved water molecule inside the carbohydrate binding site that is interacting mainly with the
2-OH group of the sugar ring. When the standard FimH ligand MeMan (1) is compared with the D-manno-configured $C$-glycosyl-type glycoconjugates 9 and 10, emerging from Amadori rearrangement of the corresponding heptopyranose $\mathbf{8}$, the axial methoxy moiety in MeMan (1) can be correlated with the equally axial oriented anomeric $\mathrm{OH}$ group of the Amadori products (Figure 2A). Then however, the equatorial anomeric $(\mathrm{N}$-alkyl/aryl amino)methylene groups in $\mathbf{9}$ and $\mathbf{1 0}$ cause a steric clash in the binding pocket because of their bulkiness. To avoid this steric conflict, the Amadori products could be flipped such that the bulky aminomethyl substituent is pointing outwards of the sugar binding site (Figure 2B). But then, the anomeric hydroxy group might be sterically hindering. In addition, proper complexation of the sugar ring will be hampered due to considerable alteration of the 3D pattern of ring hydroxy groups available for hydrogen bonding. Thirdly finally, the Amadori product could be tilted such that a complexation mode results as depicted in Figure 2C. The latter binding mode suggests that binding of D-manno-configured Amadori rearrangement products within the FimH CRD might be possible and that Amadori products could indeed function as antagonists of natural FimH.

\section{Docking of Amadori products $\mathbf{9}$ and $\mathbf{1 0}$ into the carbohydrate binding site of FimH}

In order to visualise the complexation of Amadori rearrangement products 9 and 10, respectively, inside the binding pocket

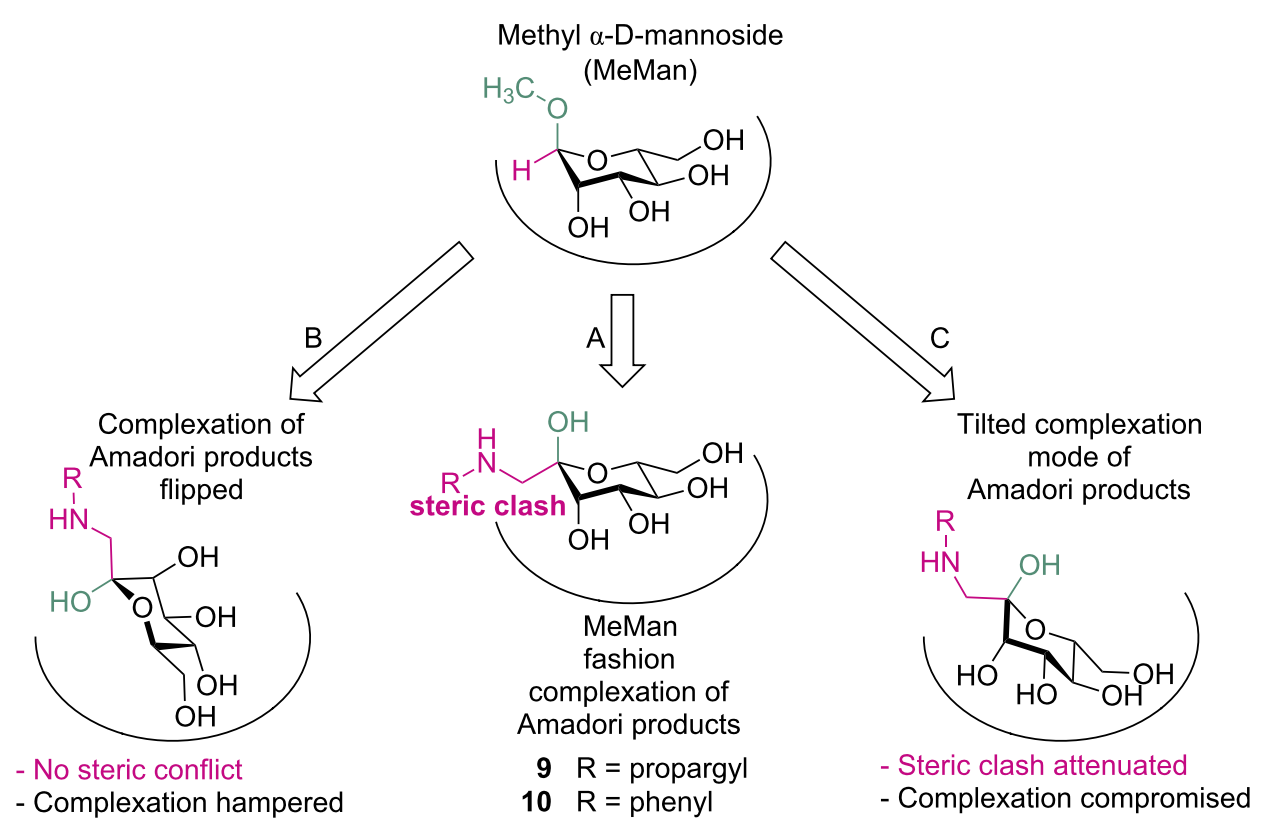

Figure 2: Cartoon illustrating ligand binding by the bacterial lectin FimH. Complexation of D-manno-configured C-glycosyl-type glycoconjugates inside the carbohydrate recognition domain (CRD) of FimH in analogy to MeMan (1, top) is hampered by the bulky $C$-glycosidic substituents in $\beta$-position, resulting in a steric clash (A). Rotation of the Amadori product averts steric conflict, yet causing insufficient complexation inside the binding pocket (B). Compromised complexation and attenuation of steric conflict may be achieved by a tilted orientation of the mannoside within the FimH carbohydrate binding site (C). 
of FimH, flexible ligand docking studies were performed using the program Glide [21-24] as implemented in the Schrödinger program package (cf. Supporting Information File 1). For these studies we utilized the so-called open gate crystal structure of FimH [10]. Here, the tyrosine gate that is formed by the side chains of Y48 and Y137 at the entrance of the CRD, has an open conformation. Prior to docking, energies of the Amadori ligands were minimised with the program MacroModel [25] and afterwards 23 different conformers of 9 and 20 conformers of 10, respectively, were generated with ConfGen $[26,27]$ by using default settings. Next, these conformers were docked holding the FimH CRD fixed whereas conformational changes were allowed for the docked ligands under the influence of the force field. The resulting docking scores were calculated with the SP (single precision) scoring function and correlated with the binding affinity of the ligand for the FimH CRD. More negative scores indicate higher binding affinity than less negative values (Table 1).

According to this docking procedure, Amadori products 9 and $\mathbf{1 0}$ have similar scores, which lie in the range of that for MeMan (1). A somewhat weaker complexation is predicted for $\mathbf{9}$ and $\mathbf{1 0}$ than for $\mathbf{1}$. We had expected $\mathbf{1 0}$ to score clearly better than $\mathbf{9}$,
Table 1: Docking scoring values of the most stable conformers complexed by FimH (open gate structure PDB 1KLF) of MeMan (1) in comparison with Amadori rearrangement products.

\begin{tabular}{ll} 
Compound & Scoring value \\
\hline MeMan (1) & -6.6 \\
9 & -4.2 \\
10 & -5.7
\end{tabular}

owing to the possibility of $\pi-\pi$ interactions between the phenyl substituent in $\mathbf{1 0}$ and the tyrosine gate at the entrance of the FimH CRD. However, this seems not to be the case.

We took a closer look at the docking results by comparing top scoring conformations of the different ligands (Figure 3). No difference between complexation of the Amadori products 9 and $\mathbf{1 0}$ and MeMan (1) can be seen when inspected from above the CRD. However, the side view clearly shows that the Amadori products are tilted in comparison to MeMan and somewhat lifted from the binding site (Figure $3 \mathrm{~B}$ and $\mathrm{C}$ ). When the respective anomeric centres are taken as a reference, 9 is lifted by $0.5 \AA$ and $\mathbf{1 0}$ by $0.7 \AA$ in comparison with complexed
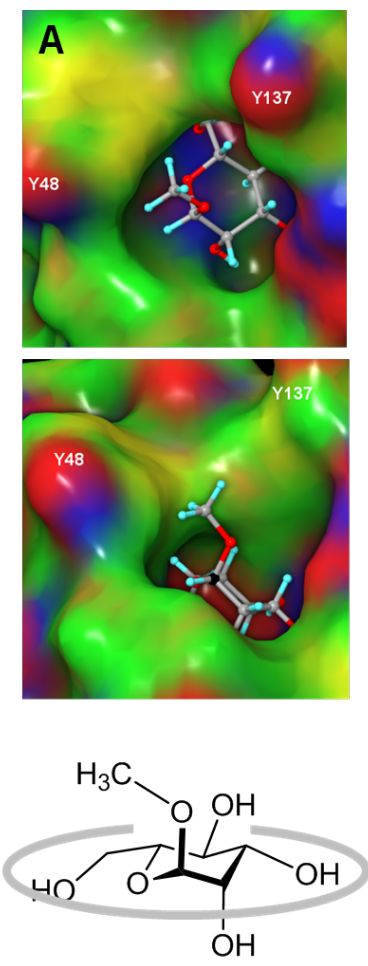

MeMan (1)
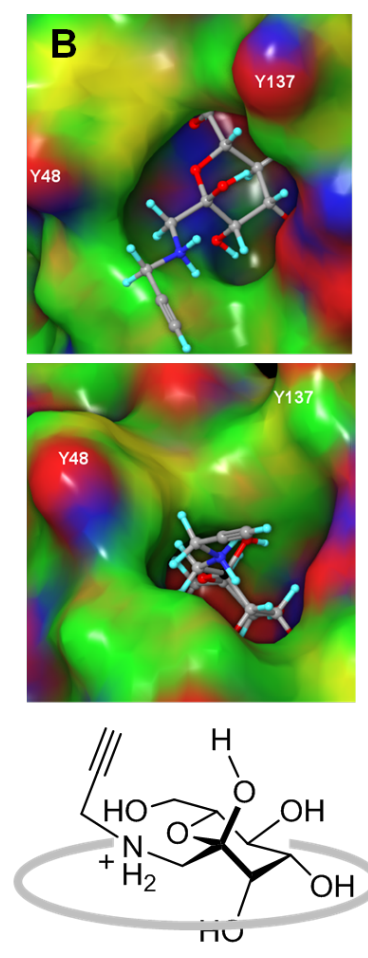

9
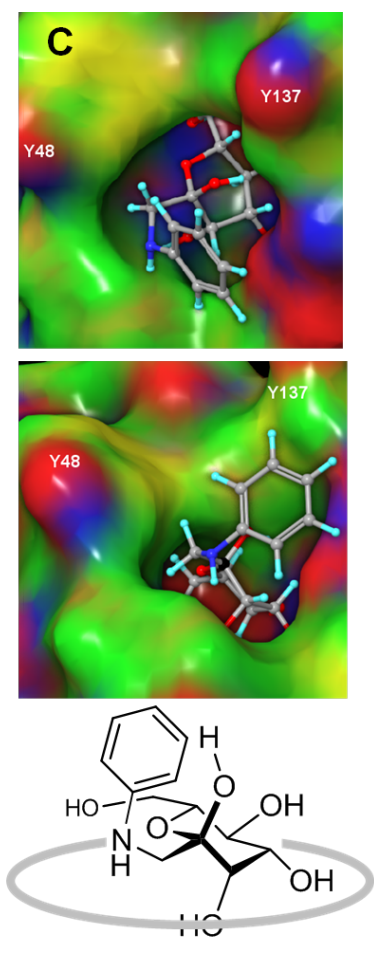

10

Figure 3: Partial charge coloured Connolly descriptions [28,29] (negative partial charges coloured in red, positive in blue) of mannoside MeMan (1) (A) and the Amadori products 9 (B) and 10 (C) as complexed within the CRD of FimH (PDB 1KLF, open gate structure). Top row: view from above the CRD; middle row: side view, with respective anomeric carbon atoms highlighted in black; bottom row cartoons (not to scale) correspond to side views and are drawn to illustrate that Amadori products $\mathbf{9}$ and $\mathbf{1 0}$ are lifted from the carbohydrate binding site resulting in diminished affinity. 
MeMan. The tilting effect apparently also prevents effective $\pi-\pi$ interactions between the FimH tyrosine gate and Amadori product $\mathbf{1 0 .}$

The effect of tilting of Amadori products $\mathbf{9}$ and $\mathbf{1 0}$ upon FimH complexation can also be analyzed by comparison of hydrogen bonding in the complex. Close inspection of the H-bond network reveals that the average length of $\mathrm{H}$-bonds established with 9 and 10, respectively, is higher and thus the formed $\mathrm{H}$-bonds are weaker than in the case of MeMan complexation. In addition, $\mathbf{9}$ and $\mathbf{1 0}$ cannot interact with the water molecule that is conserved in the FimH binding site (Figure 4).

\section{Biological testing of Amadori products 9 and 10}

To check the predictions made by molecular docking, inhibition-adhesion studies using type 1-fimbriated fluorescent E. coli were performed [30]. Accordingly, the manno-config- ured glycosides $\mathbf{9}$ and $\mathbf{1 0}$ were used as inhibitors of FimH-mediated bacterial adhesion to mannan employing a microtiter plate format and GFP-transfected E. coli (pPKL1162). Serial dilutions of rearrangement products $\mathbf{9}$ and $\mathbf{1 0}$ in buffer were used to deliver sigmoidal inhibition curves from which $\mathrm{IC}_{50}$ values for both inhibitors were deduced (cf. Supporting Information File 1). The $\mathrm{IC}_{50}$ value of an inhibitor is the concentration at which $50 \%$ of bacterial adhesion is prevented. All assays were performed with MeMan (1) tested in parallel on the same plate. This allows to correlate the inhibitory potencies of $\mathbf{9}$ and $\mathbf{1 0}$ to that of MeMan (1) and report so-called relative inhibitory potencies (RIP values). This procedure allows to compare inhibitors even when they were not tested on the same plate. The results from the adhesion-inhibition assays are listed in Table 2. Both Amadori products 9 and $\mathbf{1 0}$ showed a lower inhibitory power than MeMan $\left(1, \mathrm{IC}_{50} \equiv 1\right)$. Thus, they have to be regarded as weak ligands for FimH. Unexpectedly, the propynyl derivative 9 has a slightly higher inhibitory power
A

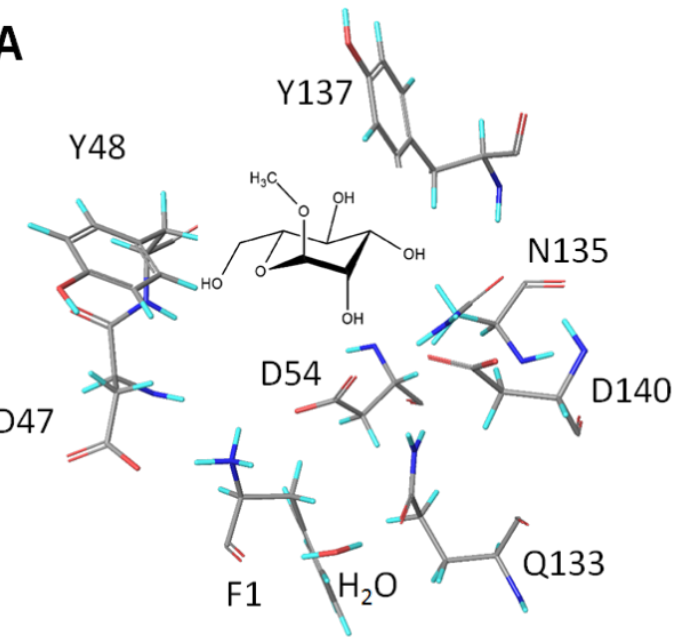

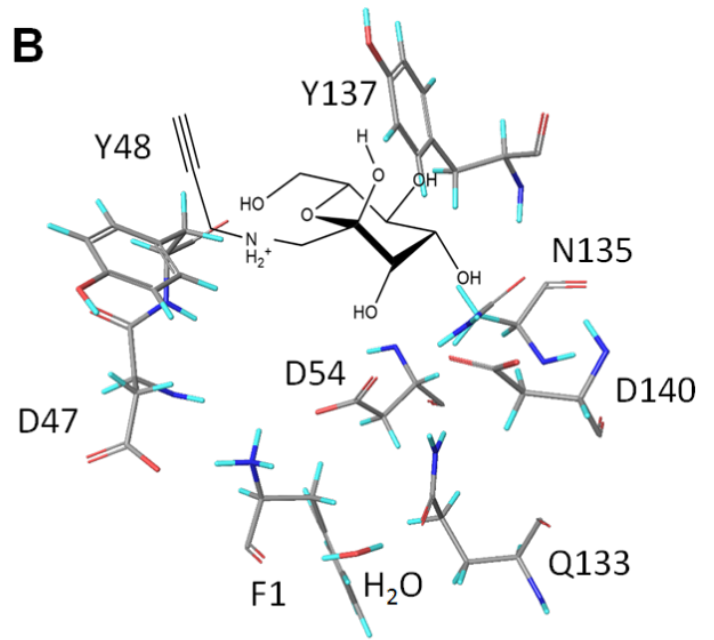

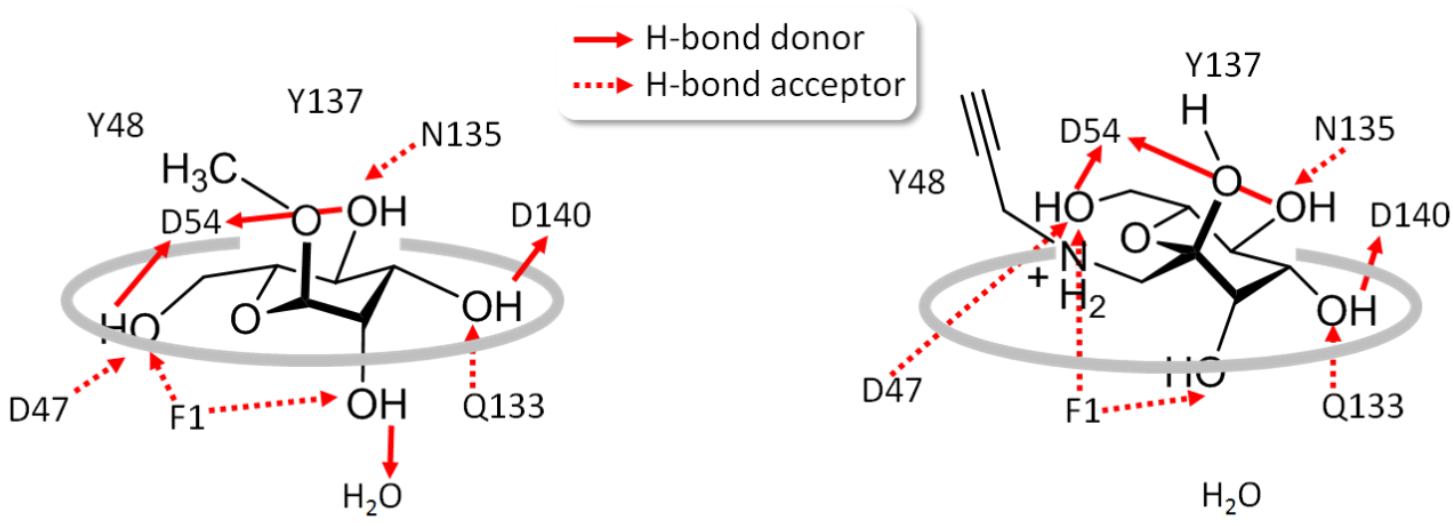

Figure 4: Comparison of mannosides as complexed within the CRD of FimH (PDB 1KLF). A: MeMan (1); B: Amadori product 9. The top graphics show the result of the simulated 3D-arrangement of amino acid residues of the FimH CRD with docked 2D-cartoons of MeMan (1, left) and the Amadori product 9 (right). The bottom cartoons are deduced from the docking result illustrating the predicted hydrogen bond network between amino acid side chains and the sugar hydroxy groups (not to scale). 
than the Amadori product 10, having a phenyl-containing aglycone. This again shows, that the tilted complexation mode apparently compromises the possibility of favorable $\pi-\pi$ interaction.

Table 2: Inhibition of bacterial adhesion (E. coli) to a mannan-coated surface. The inhibitory potencies of Amadori rearrangement products are compared to the standard inhibitor MeMan (1). ${ }^{a}$

9

\begin{tabular}{lcc}
\hline $\mathrm{IC}_{50} \pm \mathrm{SD}(\mathrm{mM})$ & $7.625 \pm 1.146$ & $10.811 \pm 1.470$ \\
$\mathrm{RIP}($ MeMan, 1) & 0.41 & 0.16 \\
\hline
\end{tabular}

asD: standard deviation (from one assay); RIP: relative inhibitory potency referenced to MeMan (1, tested on the same microtiter plate).

\section{Conclusion}

The Amadori rearrangement has the potential as a straight forward ligation method for conjugation of unprotected sugars and amines, when applied to suitable sugar substrates. Herein, we evaluated this synthetic method for the preparation of ligands for the $\alpha$-D-mannose-specific type 1-fimbrial bacterial lectin FimH. The synthesis of heptopyranose $\mathbf{8}$ as a starting material for manno-configured $C$-glycosyl-type hexoses via the Amadori rearrangement was reported. We have employed propargylamine and aniline to prepare 9 and 10, respectively. They carry an anomeric hydroxy group positioned to the $\alpha$-face of the sugar ring and a rather bulky $\beta$-positioned alkyl/aryl aminomethyl group at the anomeric centre. Molecular docking of both Amadori products, $\mathbf{9}$ and 10, into FimH suggested a reasonable binding mode, however in biological testing $\mathbf{9}$ and $\mathbf{1 0}$ showed an approx. 0.4 and 0.2 fold weaker potency as inhibitors of FimH-mediated bacterial adhesion than MeMan (1). This can be explained by the tilted fashion in which Amadori products are complexed by FimH. They are lifted from the bottom of the CRD and this results in compromised H-bonding and weak affinity.

We learn from this interdisciplinary study that it is critical to utilize the Amadori rearrangement for the synthesis of FimH ligands because it delivers products with a limited fit for this lectin. FimH complexation of D-manno-configured Amadori products is challenged by the steric requirements of the $C$-glycosidic aglycone. At the same time we have characterized FimH binding of a novel ligand type that encourages further development, driven by the simple synthetic availability of this type of mannoside.

\section{Experimental}

\section{Materials and general methods}

All chemicals were purchased from Sigma-Aldrich and used without further purification. Moisture-sensitive reactions were carried out under nitrogen in dry glassware. ${ }^{1} \mathrm{H}$ and ${ }^{13} \mathrm{C}$ NMR spectra were recorded on Bruker DRX-500 and AV-600 spectrometers at $300 \mathrm{~K}$ and 500.13 and $125.75 \mathrm{MHz}$, respectively. Chemical shifts are reported relative to internal tetramethylsilane $(\delta=0.00 \mathrm{ppm})$ or $\mathrm{D}_{2} \mathrm{O}(\delta=4.76 \mathrm{ppm})$. Full assignment of the peaks was achieved with the aid of 2D NMR techniques $\left({ }^{1} \mathrm{H},{ }^{1} \mathrm{H}-\mathrm{COSY}\right.$ and $\left.{ }^{1} \mathrm{H},{ }^{13} \mathrm{C}-\mathrm{HSQC}\right)$. ESI mass spectra were recorded on an Esquire-LC instrument from Bruker Daltonics. Optical rotations were measured with a Perkin-Elmer 341 polarimeter (sodium D-line: $589 \mathrm{~nm}$, length of cell: $1 \mathrm{dm}$, temp.: $20^{\circ} \mathrm{C}$ ) in the solvents indicated. Thin-layer chromatography was performed on precoated silica gel plates on aluminum 60 F254 (E. Merck 5554). Detection was effected by UV and/or charring with $10 \%$ sulfuric acid in EtOH and/or with ceric ammonium molybdate (100 $\mathrm{g}$ ammonium molybdate/8 $\mathrm{g}$ ceric sulfate in $1 \mathrm{~L} 10 \% \mathrm{H}_{2} \mathrm{SO}_{4}$ ) followed by heat treatment at $\approx 180{ }^{\circ} \mathrm{C}$. Flash chromatography was performed on silica gel 60 (0.035-0.070 mm, 60 A, Acros Organics 24036) using distilled solvents. For biological testing, black MaxiSorp ${ }^{\mathrm{TM}}$ plates were used from Nunc ${ }^{\mathrm{TM}}$ (Thermo Scientific ${ }^{\mathrm{TM}}$ ). Bacterial adhesion studies were performed according to the literature [30], using a Tecan infinite ${ }^{\circledR} 200$ multifunction microplate reader. The band pass filters' wavelength for excitation was $485 \mathrm{~nm}$ and $535 \mathrm{~nm}$ for emission.

2,5-Di- $O$-acetyl-3,4:6,7-di-O-isopropylidene-D-glycero-Dgalacto/D-talo-heptopyranose (7a, $7 \mathbf{b})$ : To a solution of a C-3 diastereomeric mixture of protected oct-1-enitol derivative 6 $[16,17](4.0 \mathrm{~g}, 11 \mathrm{mmol})$ in a solvent mixture of $\mathrm{CH}_{2} \mathrm{Cl}_{2} / \mathrm{MeOH}$ $(80 \mathrm{~mL}, 1: 1 \mathrm{v} / \mathrm{v}), \mathrm{NaOAc}(2.4 \mathrm{~g}, 30 \mathrm{mmol}, 2.8$ equiv) was added. This reaction mixture was treated with ozone at $-50{ }^{\circ} \mathrm{C}$ for $6 \mathrm{~h}$. After TLC (Cy/EtOAc, 1:1 v/v) confirmed complete consumption of the starting material, nitrogen was bubbled through the reaction mixture for $15 \mathrm{~min}$ and the solution was allowed to reach room temperature, followed by addition of $\mathrm{Me}_{2} \mathrm{~S}$ (8.0 mL, $0.11 \mathrm{~mol}, 10$ equiv) and stirring at $\mathrm{rt}$ for $45 \mathrm{~min}$. The solvents were removed under reduced pressure and the obtained C-2 diastereomeric mixture of protected aldoheptoses 7a and $7 \mathbf{b}$ was used for the next step without further purification. The NMR data of the crude material confirmed signals in the expected regions.

D-glycero-D-galacto/D-talo-heptopyranose $(8 \mathrm{a}, 8 \mathrm{~b})$ : To a solution of a C-2-epimeric mixture of compounds $7 \mathbf{a}$ and $7 \mathbf{b}$ (8.55 g, containing $\mathrm{Me}_{2} \mathrm{~S}$ ) in $\mathrm{MeOH}(70 \mathrm{~mL})$, a solution of $\mathrm{NaOMe}(1.0 \mathrm{M}$ in $\mathrm{MeOH})$ was added dropwise at rt until the $\mathrm{pH}$ of 10 was reached and the reaction mixture was stirred at $\mathrm{rt}$ for $2 \mathrm{~h}$ until TLC (Cy/EtOAc, 1:2 v/v) showed complete consumption of the starting material. The reaction mixture was neutralized by addition of ion exchange resin (Amberlite IR 120 $\mathrm{H}^{+}$, washed with $\mathrm{MeOH}$ ). The resin was filtered off, the filtrate 
was concentrated under reduced pressure and the crude product was purified by column chromatography (Cy/EtOAc, 4:1 v/v) to obtain a mixture of isopropylidene-protected D-galacto/D-taloheptopyranose (3.08 g, $10.6 \mathrm{mmol}$ ) in $99 \%$ overall yield starting from compound 6 . The NMR data are in accordance with those reported [19]. To a solution of 3,4:6,7-di- $O$-isopropylideneprotected heptose $(2.50 \mathrm{~g}, 8.61 \mathrm{mmol})$ in a mixture of $\mathrm{MeCN} /$ $\mathrm{H}_{2} \mathrm{O}(50 \mathrm{~mL}, 1: 1 \mathrm{v} / \mathrm{v}$ ), acidic ion exchange resin (Amberlite IR $120 \mathrm{H}^{+}$, washed with $\mathrm{H}_{2} \mathrm{O}$ ) was added until a $\mathrm{pH}$ of 2 was reached and the reaction mixture was stirred at $40{ }^{\circ} \mathrm{C}$ for $1 \mathrm{~h}$. After TLC $\left(\mathrm{CHCl}_{3} / \mathrm{MeOH} /\right.$ concd. $\left.\mathrm{NH}_{4} \mathrm{OH}, 1 / 2 / 1 \mathrm{v} / \mathrm{v} / \mathrm{v}\right)$ showed complete consumption of the starting material, the resin was filtered off and the filtrate was concentrated under reduced pressure. Column chromatography $\left(\mathrm{CHCl}_{3} / \mathrm{MeOH}\right.$ 10:1 v/v) gave D-glycero-D-galacto/D-talo-heptopyranoses $8 \mathbf{a}$ and $\mathbf{8 b}$ (1.55 g, $7.39 \mathrm{mmol})$ in a yield of $86 \%$. The NMR data are in accordance with those reported $[2,3]$.

1-(N-Propargyl)amino-1-deoxy- $\alpha$-D-manno-hept-2-ulose (9): To a solution of D-glycero-D-galacto/D-talo-heptose $\mathbf{8 a}$ and $\mathbf{8 b}$ $(467 \mathrm{mg}, 2.22 \mathrm{mmol})$ in a mixture of EtOH $(7 \mathrm{~mL}), 1,4$-dioxane (1 $\mathrm{mL})$ and water (2 drops), propargylamine $(142 \mu \mathrm{L}$, $2.22 \mathrm{mmol}, 1.0$ equiv) and acetic acid $(127 \mu \mathrm{L}, 2.22 \mu \mathrm{mol}$, 1.0 equiv) were added and the reaction mixture was stirred at $70{ }^{\circ} \mathrm{C}$ for two days. Complete consumption of the starting material was indicated by $\mathrm{TLC}\left(\mathrm{CHCl}_{3} / \mathrm{MeOH} / \mathrm{NH}_{4} \mathrm{OH}\right.$, $1: 2: 1 \mathrm{v} / \mathrm{v} / \mathrm{v})$. The solvents were removed under reduced pressure and subsequent column chromatography $\left(\mathrm{CHCl}_{3} / \mathrm{MeOH}\right.$, $8: 1 \mathrm{v} / \mathrm{v}$ containing $1 \%$ of concd. $\left.\mathrm{NH}_{4} \mathrm{OH}\right)$ gave 1-propargylamino-modified ketose 9 (420 $\mathrm{mg}, 1.70 \mathrm{mmol})$ in a yield of 77\%. $[\alpha]_{\mathrm{D}}+13.2$ (c 2.5, MeOH); ${ }^{1} \mathrm{H}$ NMR $(500 \mathrm{MHz}, \mathrm{MeOH}-$ $\left.d_{4}\right) \delta 3.84(\mathrm{dd}, 1 \mathrm{H}, \mathrm{H}-4), 3.82\left(\mathrm{dd}, J_{7,6}=2.2 \mathrm{~Hz}, 1 \mathrm{H}, \mathrm{H}-7\right), 3.80$ $\left(\mathrm{d}, J_{3,4}=3.3 \mathrm{~Hz}, 1 \mathrm{H}, \mathrm{H}-3\right), 3.74\left(\mathrm{dd}, J_{7,7},=11.5 \mathrm{~Hz}, J_{7}, 6=5.5\right.$ Hz, 1H, H-7'), 3.72-3.69 (m, 1H, H-6), 3.62 (dd, $J_{4,5}=9.4 \mathrm{~Hz}$, $\left.J_{5,6}=9.5 \mathrm{~Hz}, 1 \mathrm{H}, \mathrm{H}-5\right), 3.58$ (d, 2H, H-8), 3.10 (d, $J_{1,1}$, = 12.3 $\mathrm{Hz}, 1 \mathrm{H}, \mathrm{H}-1), 2.96$ (d, 1H, H-1'), 2.76 (t, 1H, H-10); ${ }^{13} \mathrm{C}$ NMR $\left(125 \mathrm{MHz}, \mathrm{MeOH}-d_{4}\right) \delta 97.4$ (C-2), 80.3 (C-9), 74.8 (2C, C-3, C-6), 74.5 (C-10), 72.9 (C-4), 68.2 (C-5), 62.8 (C-7), 55.4 $(\mathrm{C}-1), 38.6(\mathrm{C}-8)$; ESIMS $(\mathrm{m} / \mathrm{z})$ : calcd for $\left[\mathrm{C}_{10} \mathrm{H}_{17} \mathrm{NO}_{6}+\mathrm{H}\right]^{+}$, 248.1134; found, $248.113[\mathrm{M}+\mathrm{H}]^{+}$.

1-(N-Phenyl)amino-1-deoxy- $\alpha$-D-manno-hept-2-ulose (10): To a solution of D-glycero-D-galacto/D-talo-heptopyranoses $\mathbf{8 a}$ and $\mathbf{8 b}(110 \mathrm{mg}, 523 \mu \mathrm{mol})$ in a mixture of EtOH $(1 \mathrm{~mL}), 1,4-$ dioxane $(0.2 \mathrm{~mL})$ and water $(2$ drops $)$, aniline $(47.8 \mu \mathrm{L}$, $523 \mu \mathrm{mol}, 1.0$ equiv) and acetic acid $(30.0 \mu \mathrm{L}, 523 \mu \mathrm{mol}$, 1.0 equiv) were added and the reaction mixture was stirred at $70{ }^{\circ} \mathrm{C}$ for $48 \mathrm{~h}$. Complete consumption of the starting material was indicated by $\mathrm{TLC}\left(\mathrm{CHCl}_{3} / \mathrm{MeOH} / \mathrm{NH}_{4} \mathrm{OH}\right.$, 1:2:1 v/v/v). The solvents were removed under reduced pressure and subsequent column chromatography $\left(\mathrm{CHCl}_{3} / \mathrm{MeOH}\right.$,
$8: 1 \mathrm{v} / \mathrm{v}$ containing $1 \%$ of concd. $\mathrm{NH}_{4} \mathrm{OH}$ ) gave 1-phenylamino ketose $10(35.0 \mathrm{mg}, 123 \mu \mathrm{mol})$ in a yield of $24 \%$. $[\alpha]_{\mathrm{D}}+21.5(c$ $0.76, \mathrm{MeOH}) ;{ }^{1} \mathrm{H}$ NMR (500 MHz, MeOH- $\left.d_{4}\right) \delta 7.11$ (dd, $2 \mathrm{H}$, phenyl), 6.75 (d, 2H, phenyl), 6.65 (dd, 1H, phenyl), 3.90 (dd, $\left.J_{3,4}=3.3 \mathrm{~Hz}, J_{4,5}=9.4 \mathrm{~Hz}, 1 \mathrm{H}, \mathrm{H}-4\right), 3.85(\mathrm{~d}, 1 \mathrm{H}, \mathrm{H}-3)$, 3.87-3.83 (m, 1H, H-7), 3.78-3.76 (m, 1H, H-6), 3.75 (dd, $J_{6,7}$, $=5.3 \mathrm{~Hz}, J_{7,7}$, = $\left.13.7 \mathrm{~Hz}, 1 \mathrm{H}, \mathrm{H}-7^{\prime}\right), 3.63\left(\mathrm{dd}, J_{5,6}=9.5 \mathrm{~Hz}\right.$, $1 \mathrm{H}, \mathrm{H}-5), 3.43$ (d, $J_{1,1}$, = $\left.12.7 \mathrm{~Hz}, 1 \mathrm{H}, \mathrm{H}-1\right), 3.27$ (d,1H, H-1'); ${ }^{13} \mathrm{C}$ NMR $\left(125 \mathrm{MHz}, \mathrm{MeOH}-d_{4}\right) \delta 150.2,130.0,118.7,114.8$ (6C, phenyl), 98.9 (C-2), 74.9 (C-6), 73.3 (C-3), 72.9 (C-4), 68.7 (C-5), 63.0 (C-7), $51.4(\mathrm{C}-1)$. ESIMS $(\mathrm{m} / \mathrm{z})$ : calcd for $\left[\mathrm{C}_{13} \mathrm{H}_{19} \mathrm{NO}_{6}+\mathrm{H}\right]^{+}$, 286.1291; found, $286.129[\mathrm{M}+\mathrm{H}]^{+}$.

\section{Supporting Information}

\section{Supporting Information File 1}

NMR spectra, boiassays and molecular docking.

[http://www.beilstein-journals.org/bjoc/content/

supplementary/1860-5397-11-123-S1.pdf]

\section{Acknowledgements}

We are grateful to Claudia Fessele, M.Sc., for advice with the biological experiments. Financial support by the DFG (Germany) and the FWF (Austria”, I 945-B21") in the frame of an ERA-Chemistry grant is gratefully acknowledged. This work was supported by NAWI Graz.

\section{References}

1. Wrodnigg, T. M.; Eder, B. The Amadori and Heyns Rearrangements: Landmarks in the History of Carbohydrate Chemistry or Unrecognized Synthetic Opportunities?. In Glycoscience - Epimerization, Isomerization, Rearrangement Reactions of Carbohydrates; Stütz, A. E., Ed.; Topics in Current Chemistry, Vol. 215; Springer-Verlag: Berlin, Heidelberg, New York, 2001; pp 115-152. doi:10.1007/3-540-44422-x_6

2. Wrodnigg, T. M.; Kartusch, C.; Illaszewicz, C. Carbohydr. Res. 2008, 343, 2057-2066. doi:10.1016/j.carres.2008.02.022

3. Gallas, K.; Pototschnig, G.; Adanitsch, F.; Stütz, A. E.; Wrodnigg, T. M. Beilstein J. Org. Chem. 2012, 8, 1619-1629. doi:10.3762/bjoc.8.185

4. Hartmann, M.; Lindhorst, T. K. Eur. J. Org. Chem. 2011, 3583-3609. doi:10.1002/ejoc.201100407

5. Autar, R.; Khan, A. S.; Schad, M.; Hacker, J.; Liskamp, R. M. J.; Pieters, R. J. ChemBioChem 2003, 4, 1317-1325. doi:10.1002/cbic.200300719

6. Sharon, N. Biochim. Biophys. Acta, Gen. Subj. 2006, 1760, 527-537. doi:10.1016/j.bbagen.2005.12.008

7. Ernst, B.; Magnani, J. L. Nat. Rev. Drug Discovery 2009, 8, 661-677. doi:10.1038/nrd2852

8. Jiang, X.; Abgottspon, D.; Kleeb, S.; Rabbani, S.; Scharenberg, M.; Wittwer, M.; Haug, M.; Schwardt, O.; Ernst, B. J. Med. Chem. 2012, 55, 4700-4713. doi:10.1021/jm300192x 
9. Choudhury, D.; Thompson, A.; Stojanoff, V.; Langermann, S.; Pinkner, J.; Hultgren, S. J.; Knight, S. D. Science 1999, 285, 1061-1066. doi:10.1126/science.285.5430.1061

10. Hung, C.-S.; Bouckaert, J.; Hung, D.; Pinkner, J.; Widberg, C.; DeFusco, A.; Auguste, C. G.; Strouse, R.; Langermann, S.; Waksman, G.; Hultgren, S. J. Mol. Microbiol. 2002, 44, 903-915. doi:10.1046/j.1365-2958.2002.02915.x

11. Bouckaert, J.; Berglund, J.; Schembri, M.; De Genst, E.; Cools, L.; Wuhrer, M.; Hung, C.-S.; Pinkner, J.; Slättegård, R.; Zavialov, A.; Choudhury, D.; Langermann, S.; Hultgren, S. J.; Wyns, L.; Klemm, P.; Oscarson, S.; Knight, S. D.; De Greve, H. Mol. Microbiol. 2005, 55, 441-455. doi:10.1111/j.1365-2958.2004.04415.x

12. Tomašić, T.; Rabbani, S.; Gobec, M.; Mlinarič Raščan, I.; Podlipnik, Č.; Ernst, B.; Anderluh, M. Med. Chem. Commun. 2014, 5, 1247-1253. doi:10.1039/C4MD00093E

13. Firon, N.; Ashkenazi, S.; Mirelman, D.; Ofek, I.; Sharon, N. Infect. Immun. 1987, 55, 472-476.

14. Imberty, A.; Chabre, Y. M.; Roy, R. Chem. - Eur. J. 2008, 14, 7490-7499. doi:10.1002/chem.200800700

15. Sperling, O.; Fuchs, A.; Lindhorst, T. K. Org. Biomol. Chem. 2006, 4, 3913-3922. doi:10.1039/b610745a

16. Kaliappan, K. P.; Das, P.; Kumar, N. Tetrahedron Lett. 2005, 46, 3037-3040. doi:10.1016/j.tetlet.2005.03.021

17. van Boggelen, M. P.; van Dommelen, B. F. G. A.; Jiang, S.; Singh, G. Tetrahedron 1997, 53, 16897-16910. doi:10.1016/S0040-4020(97)10125-9

18. Paulsen, H.; Schüller, M.; Heitmann, A.; Nashed, M. A.; Redlich, H. Liebigs Ann. Chem. 1986, 675-686. doi:10.1002/jlac.198619860409

19. Lenagh-Snow, G. M. J.; Jenkinson, S. F.; Newberry, S. J.; Kato, A.; Nakagawa, S.; Adachi, I.; Wormald, M. R.; Yoshihara, A.; Morimoto, K.; Akimitsu, K.; Izumori, K.; Fleet, G. W. J. Org. Lett. 2012, 14, 2050-2053. doi:10.1021/ol3005744

20. Wrodnigg, T. et al., unpublished results.

21. Friesner, R. A.; Banks, J. L.; Murphy, R. B.; Halgren, T. A.; Klicic, J. J.; Mainz, D. T.; Repasky, M. P.; Knoll, E. H.; Shelley, M.; Perry, J. K.; Shaw, D. E.; Francis, P.; Shenkin, P. S. J. Med. Chem. 2004, 47, 1739-1749. doi:10.1021/jm0306430

22. Halgren, T. A.; Murphy, R. B.; Friesner, R. A.; Beard, H. S.; Frye, L. L.; Pollard, W. T.; Banks, J. L. J. Med. Chem. 2004, 47, 1750-1759. doi:10.1021/jm030644s

23. Friesner, R. A.; Murphy, R. B.; Repasky, M. P.; Frye, L. L.; Greenwood, J. R.; Halgren, T. A.; Sanschagrin, P. C.; Mainz, D. T. J. Med. Chem. 2006, 49, 6177-6196. doi:10.1021/jm051256o

24. Small-Molecule Drug Discovery Suite 2013-3: Glide, version 6.1; Schrödinger, LLC: New York, NY, 2013.

25. MacroModel, version 10.2; Schrödinger, LLC: New York, NY, 2013.

26. Watts, K. S.; Dalal, P.; Murphy, R. B.; Sherman, W.; Friesner, R. A.; Shelley, J. C. J. Chem. Inf. Model. 2010, 50, 534-546. doi:10.1021/ci100015j

27. ConfGen, version 2.6; Schrödinger, LLC: New York, NY, 2013.

28. Connolly, M. L. Science 1983, 221, 709-713. doi:10.1126/science.6879170

29. Connolly, M. L. J. Appl. Crystallogr. 1983, 16, 548-558. doi:10.1107/S0021889883010985

30. Hartmann, M.; Horst, A. K.; Klemm, P.; Lindhorst, T. K. Chem. Commun. 2010, 46, 330-332. doi:10.1039/B922525K

\section{License and Terms}

This is an Open Access article under the terms of the Creative Commons Attribution License

(http://creativecommons.org/licenses/by/2.0), which permits unrestricted use, distribution, and reproduction in any medium, provided the original work is properly cited.

The license is subject to the Beilstein Journal of Organic Chemistry terms and conditions:

(http://www.beilstein-journals.org/bjoc)

The definitive version of this article is the electronic one which can be found at:

doi:10.3762/bjoc. 11.123 